\title{
Evolution of open air quality of urbanized territories under Covid-19 pandemic conditions
}

\author{
Z. Z. Sobko ${ }^{1}$, N. M. Vozniuk ${ }^{2}$, O. A. Lykho ${ }^{2}$, A. M. Pryshchepa², Z. M. Budnik ${ }^{2 *}$ \\ ${ }^{1}$ Rivne Oblast Hydrometeorology Centre, 4 Gogolya St, Rivne 33028, Ukraine \\ ${ }^{2}$ National University of Water and Environmental Engineering, Department of Ecology, \\ 53a M. Karnauchova St, Ed. Building 7, Room 751, Rivne 33000, Ukraine \\ Corresponding author E-mail: z.m.budnik@nuwm.edu.ua
}

Received: 18.11.2020. Accepted: 18.12.2020

\begin{abstract}
Current state of world affairs in 2020 during quarantine enforced due to COVID-19 pandemic is characterized, on the one hand, with economic recession, but on the other hand, also with improvement of ecological state of environment. Thus a unique opportunity came up to study processes of open air conditions formation in settlements in circumstances of restricted economic activity and limitations imposed on all kinds of transportation. This article presents results of research of trends of formation of open air quality of urbanized territories (using city of Rivne as an example) during quarantine enforced due to COVID-19 pandemic. It is determined that due to introduction of quarantine measures air quality has improved. So, during the quarantine as well as after relaxation of quarantine measures only concentration of formaldehyde in open air of Rivne city did exceed average daily MAC. Primary source of open air pollution in Rivne city is motor vehicles which comprise $79 \%$ of total amount of pollutant emissions. Main pollutants which influence formation of open air quality in the city are: dust, sulfur dioxide, nitrogen dioxide, hydrogen fluoride and formaldehyde. They exceeded average daily MAC by factor of 1.3 to 32 . Complex air pollution index (CAPI) was equal to 5.4 during quarantine restrictions but grew to 5.7 when the restrictions were partially loosened. Thus, air pollution level was evaluated as "mild pollution". During the corresponding periods of 2019 this index was changing from 6.9 ("mild air pollution") to 7.7 ("polluted air") respectively. Open air pollution level is determined by a complex of constituents including pollutant emission amounts, their specifics and dependency on meteorological factors. Due to this aspect we have performed statistical examinations to determine dependency of open air pollutant concentrations on meteorological conditions using multiple correlation coefficients. Strong correlation was exhibited for nitrogen oxide, hydrogen chloride and ammonia: multiple correlation coefficients fall within $0.76-0.80$ range; moderate correlation was seen for dust, sulfur dioxide, nitrogen dioxide, hydrogen disulphide, phenol and formaldehyde with multiple correlation coefficients varying in 0.51-0.70 range.
\end{abstract}

Keywords: Open air; atmospheric air; urbanized territories; quarantine restrictions; complex air pollution index; AQI

\section{Introduction}

Quality of atmospheric air is a determinant of formation of favorable and comfortable conditions for human beings. Yet in conditions of ever growing man-induced environmental footprint, increasing motor vehicles emissions state of environment is worsening, and that applies to open air quality as well. Open air pollution is one of the major contemporary ecological challenges that manifests itself most badly within urbanized territories. Therewith, open air pollution level depends not only on volumes of industrial and motor vehicle emissions but also on the character of their vertical and horizontal dispersion which are driven first of all by meteorological conditions (Kiptenko et al., 2013).

Year 2020 has already became history as one of the years of most significant economic crisis, caused by COVID-19 pandemic, that has spread to virtually all countries of the world. Quarantine declared by World Health Organization as one of the means to decrease rate of disease propagation has resulted in decrease or suspension of production at industrial plants as well as restriction or prohibition of population movement using both mass transit and personal vehicles. Thus at this conjuncture, on one hand, economics went into recession, but on the other hand, improvement of environmental situation was observed. This is because anthropogenic load on the natural environment, including state of open air, has substantially decreased during the quarantine. Ministry of Ecology and Natural Resources of Ukraine had reported on its website after only a month of quarantine restrictions about lowered average concentrations of certain pollutants is some cities; these were: nitrogen dioxide, sulfur dioxide, airborne (suspended) dust and formaldehyde in open air.

A number of scholarly works is dedicated to research of evolution of open air quality in large cities, including works by following scientists: Y. Novikov (Novikov, 2005), V. Kucheryavy (Kucheryavy, 1999), O. Adamenko (Adamenko et al., 2004), V. Baharev (Baharev et al., 2012), M. Klymenko (Klymenko et al., 2006), A. Pryschepa (Pryschepa et al., 2017), O. Brezhytska (Brezhytska, 2013) and others.

As noted by L. Nadtochiy, roles of anthropogenic emission sources and their contribution to general dynamics of evolution of open air pollution vary substantially at different time scales. Such effects are not always univocal, complicating determination of interdependence between meteorological conditions and pollutant concentrations, therefore effect of meteorological characteristics on pollution levels must be studied separately in every city (Nadtochiy, 2020). Many scientists abroad have studied effects of meteorological conditions on athmospheric pollution levels and their temporal dynamics (Jacobson, 2002; Moller, 2010; Akimoto, 2016; Lazaridis, 2011; Liss et al., 2014; Liu et al. 2015). 


\section{Evolution of open air quality}

Scientific works by A. Hvesyk, A. Stepanenko (Hvesyk et al., 2014; 2015), Z. Herasymchuk (Herasymchuk and Oleksyuk, 2007), A. Kachynsky (Kachynsky, 2001), V. Shevchuk (Shevchuk et al. 2004) present developments of theoretical, methodological principles and applied guidances for ensuring sufficient level of ecological safety, including safety in regard to open air, for Ukraine as a whole as well as on regional basis (Boyko, 2016).

Situation that has developed in 2020 during the period of quarantine introduced due to COVID-19 pandemic is essentially unique. It provides an opportunity to study and quantify possible improvement of open air state in settlements due to restrictions of economic activities and all kinds of transportation. Therefore research in this direction is quite relevant.

\section{Materials and Methods}

Object of this work is to determine trends of evolution of open air quality in urbanized territories (using the example of Rivne city) in conditions of quarantine imposed due to COVID-19 pandemic as well as to determine role of meteorological constituents in processes that determine quality of open air.

City of Rivne is a district (oblast) center of Rivne oblast, located in northwestern part of Ukraine. City population is 246.5 thousand (as of 2019), its area is $63 \mathrm{sq} . \mathrm{km}$.

While Rivne oblast has remarkably agrarian specialization, it has quite developed industrial production. Dominant industries in region's economy are: power industry, chemical industry, consumer goods (light) industry, timber industry, food manufacturing, construction materials manufacturing, metal industry and machine-building industry. A lot of manufacturing plants are located on Rivne city territory or in its surroundings. Enterprises of Rivne city have different structure of output.

The region is intersected by international and national highways "Kyiv - Warsaw", "Kyiv - Brest", "Kyiv - Lviv", "Lviv - Zhytomyr", "Kyiv - Chernivtsi". There are $588 \mathrm{~km}$ of maintained railway track in the region as well as $7535 \mathrm{~km}$ of motor roads. Thus mobile sources of emissions make substantial contribution to pollution of open air in Rivne oblast (about 79\% of total emissions in the region), and their amounts are growing each year due to increased numbers of motor vehicles and growing traffic loads. According to data of regional Central statistics authority, total amount of pollutant emissions into open air in the region in year 2019 from stationary sources was 9.9 thousand tons, or 0.8 thousand tons greater than in 2018. Dynamics of pollutant emissions by stationary and mobile pollution sources on the territory of Rivne city during years $2000-2019$ is presented on Figure 1.

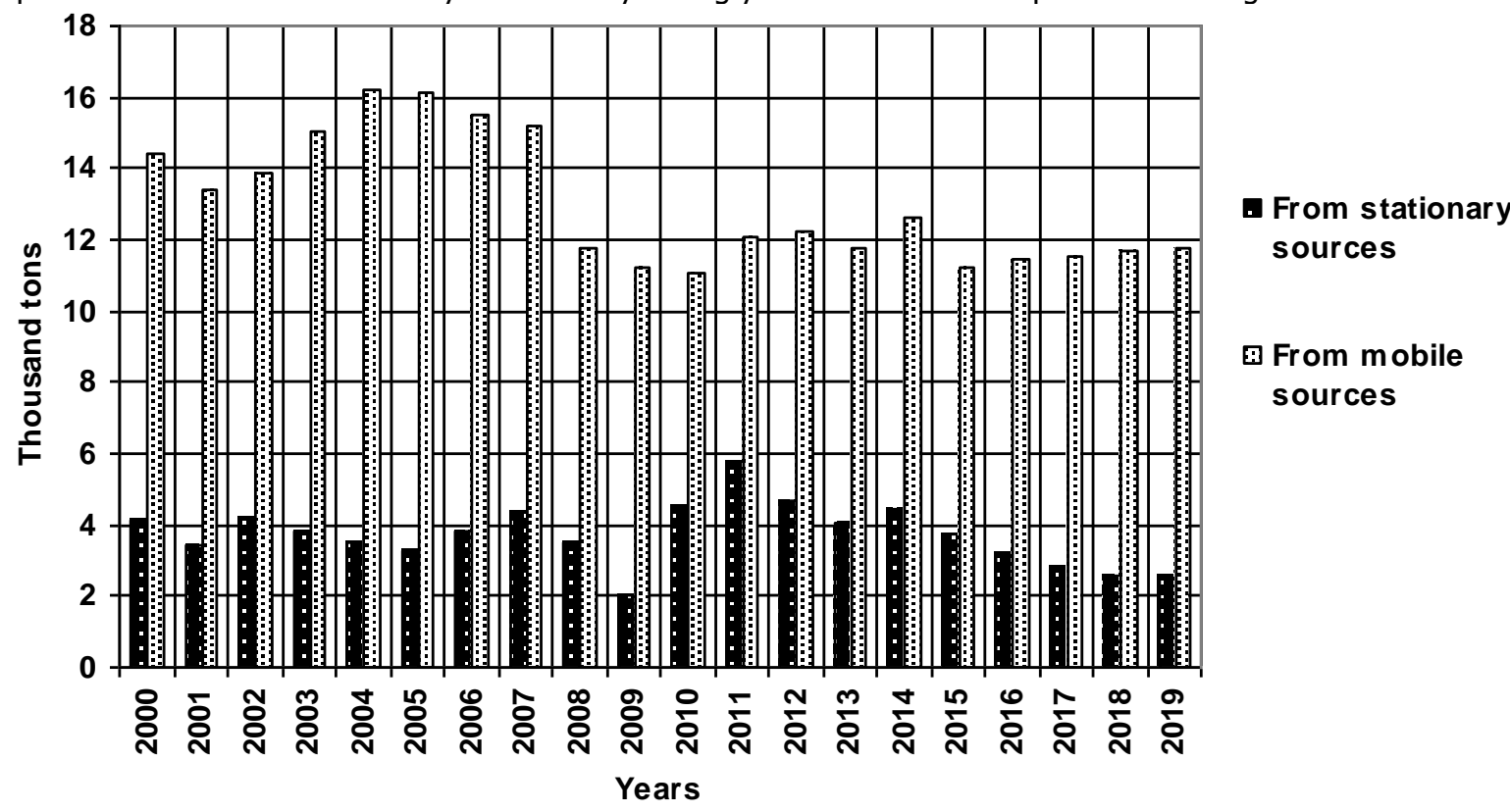

Figure 1. Dynamics of pollutant emissions into open air in Rivne city during 2000-2019 years.

Analysis of dynamics of pollutant emissions into open air in Rivne city during years 2000-2019 makes it possible to determine trend of decreasing emissions amount in Rivne city from both stationary and mobile sources. Highest amounts of stationary source emissions was observed in 2011 (5.8 thousand tons), while lowest amounts were registered in 2009 (2.1 thousand tons); for mobile sources these amounts range from 16.2 thousand tons in 2004 to 11.1 thousand tons in 2010 correspondingly. Mobile emission sources present the biggest contribution to formation of open air state in Rivne city.

Observations of open air quality in Rivne city are performed at 3 stationary monitoring stations of Rivne Oblast hydrometeorology centre. Complex laboratory in the centre determines concentration of 11 top priority pollutants: dust, sulfur dioxide, nitrogen dioxide, nitrogen oxide, carbon monoxide, hydrogen disulphide, phenol, hydrogen fluoride, hydrogen chloride, ammonia, formaldehyde. Figure 2 shows urban plan of Rivne city with marked stationary monitoring stations.

Charts presented on Figure 3 demonstrate dynamics of concentrations of top-priority pollutants in open air of Rivne city during years 2000-2019. Analysis of these graphical materials lets us come to certain conclusions. So, concentrations of dust, sulfur dioxide and nitrogen dioxide during years $2000-2009$ varied in $0.4-1.0 \mathrm{mg} / \mathrm{m}^{3}, 0.07-0.3 \mathrm{mg} / \mathrm{m}^{3}$ and $0.5-0.95 \mathrm{mg} / \mathrm{m}^{3}$ ranges correspondingly and exceeded average MAC (MACa.d.) by factor of 2.7-6.7, 1.4-6.0 and 12.5-23.8 correspondingly. Since year 2010 concentrations of dust, sulfur dioxide and nitrogen dioxide did not exceed MACa.d.

Concentrations of carbon monoxide (during years 2000-2019), nitrogen oxide, hydrogen sulfide, hydrogen chloride and ammonia (during years 2010-2019) varied in following ranges: $0.5-2.24 \mathrm{mg} / \mathrm{m}^{3}, 0.009-0.045 \mathrm{mg} / \mathrm{m}^{3}, 0.002-0.005 \mathrm{mg} / \mathrm{m}^{3}, 0.038-0.19 \mathrm{mg} / \mathrm{m}^{3}$ and $0.0002-0.017 \mathrm{mg} / \mathrm{m}^{3}$ correspondingly and did not exceed MACa.d. Concentration of phenol exceeded MACa.d. by factor of 1.33.3 (during years 2010-2013) and varied in 0.004-0.01 mg/m3 range. Most threatening situation has arisen due to pollution with hydrogen fluoride and formaldehyde - during years 2010-2019 concentration of hydrogen fluoride in open air was larger by factor of 1.2-32.0 than MACa.d., concentration of formaldehyde was larger by factor of $1.3-3.3$, and they varied within $0.006-0.016 \mathrm{mg} / \mathrm{m} 3$ and $0.004-0.01 \mathrm{mg} / \mathrm{m}^{3}$ ranges correspondingly. 


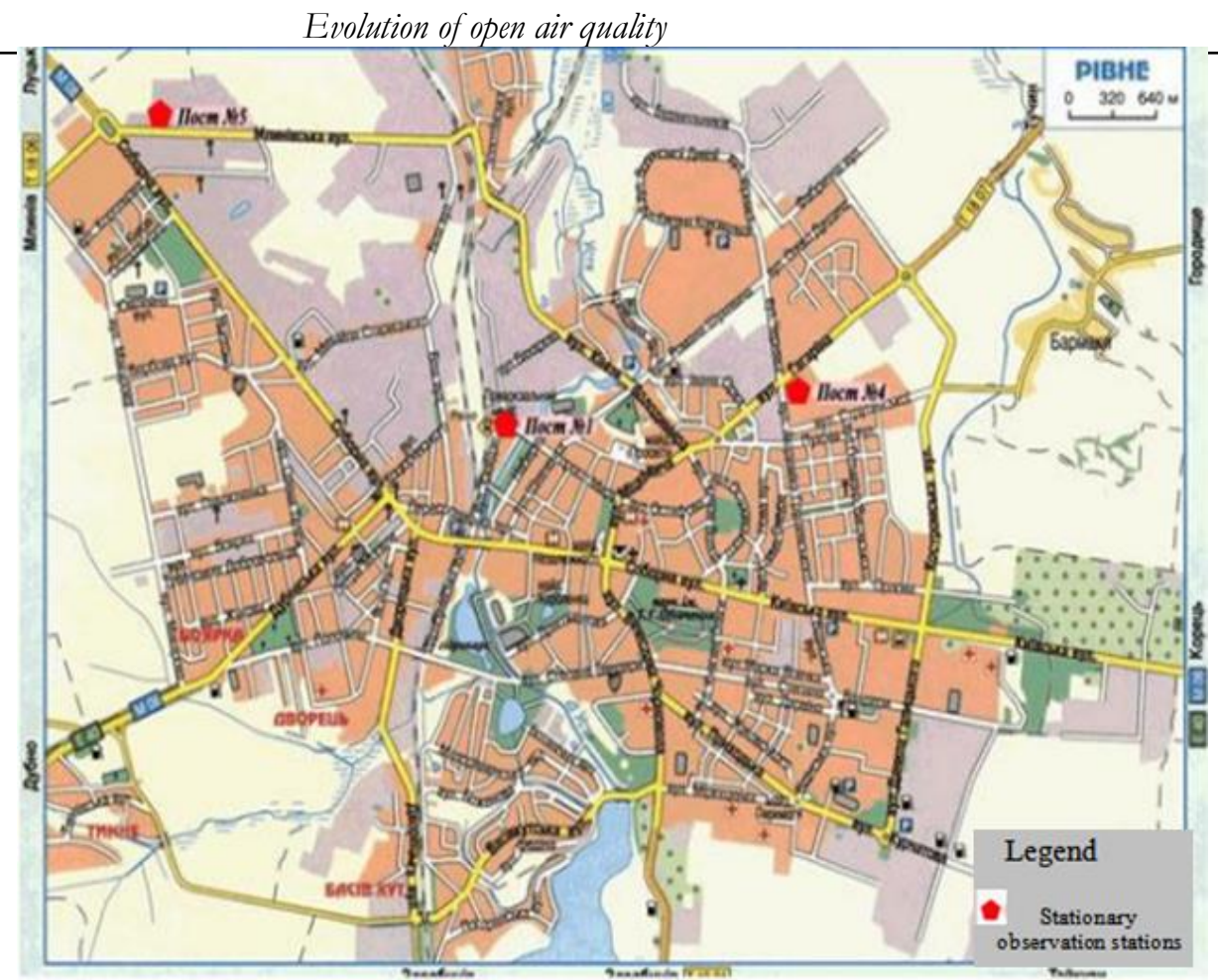

Figure 2. Urban plan of Rivne city with marked stationary monitoring stations.
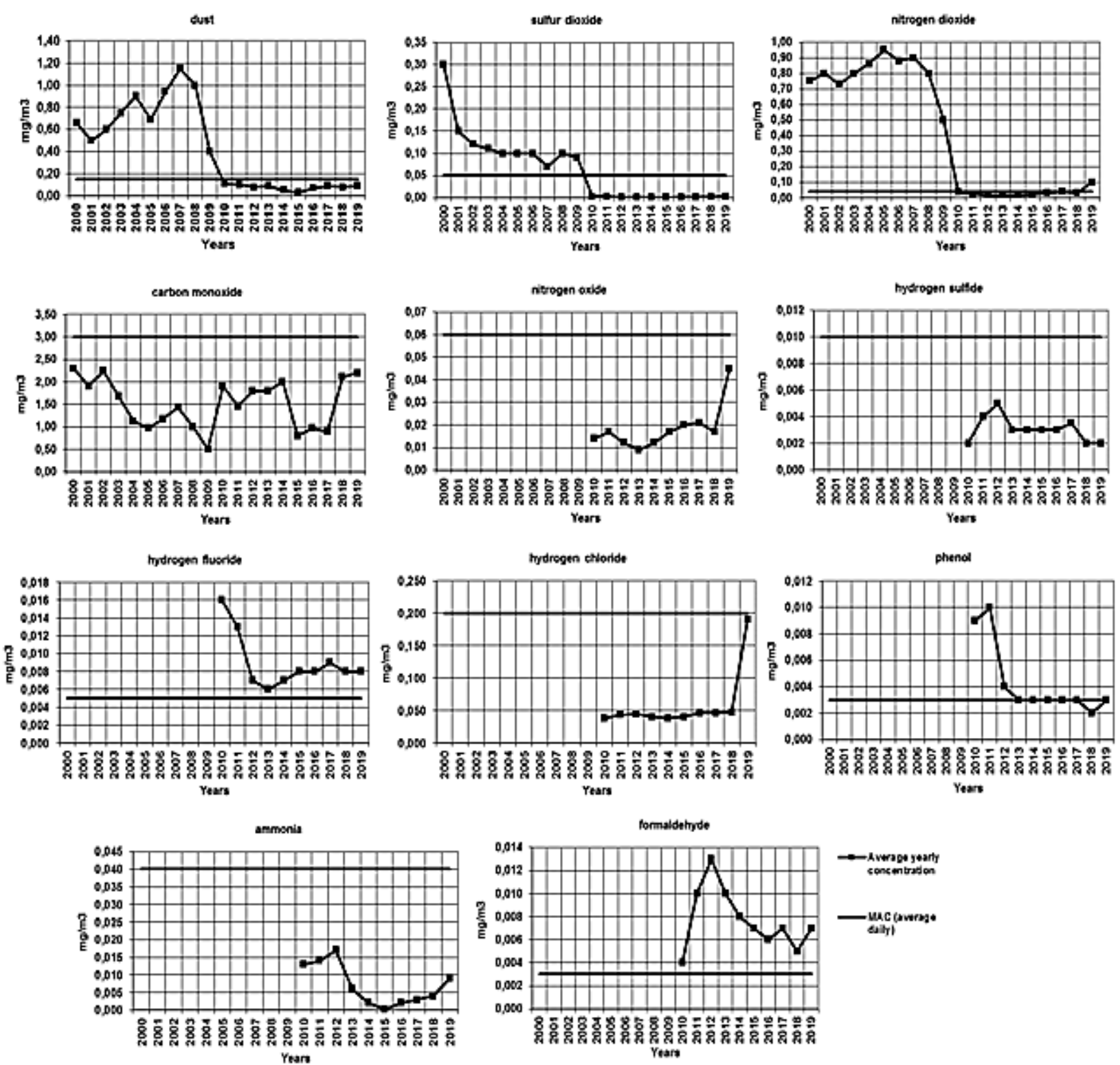

Figure 3. Dynamics of concentration of top-priority pollutants present in open air of Rivne city during 2000-2019 years. 


\section{Results and discussion}

To determine level of pollution of open air in Rivne city with top-priority pollutants, we used complex air pollution index (CAPI). Numeric index value lets one evaluate pollution level from "clean air" to "extremely polluted". Results of the study are presented on Figure 4.

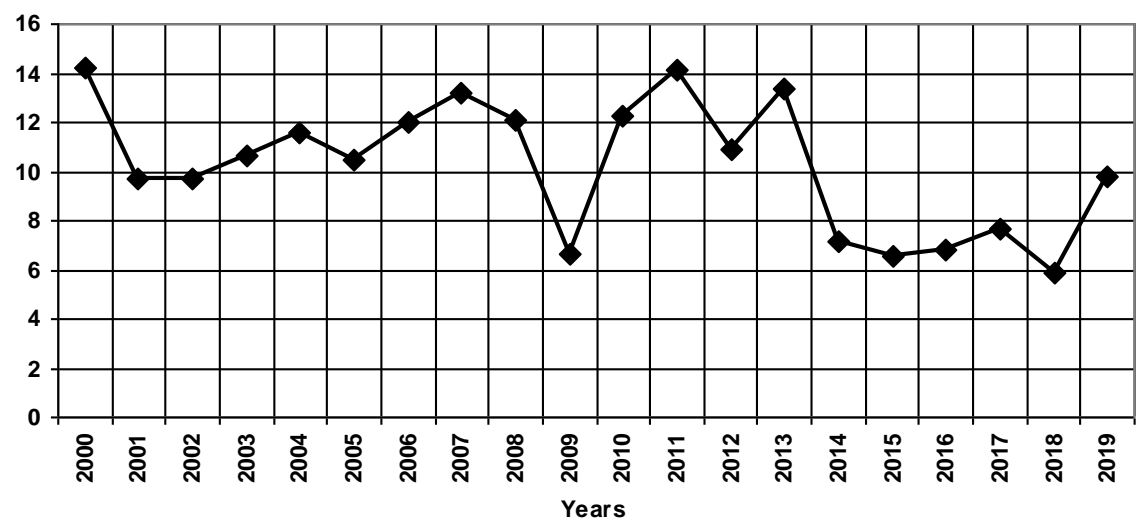

Figure 4. Dynamics of CAPI value in Rivne city during years 2000-2019.

As shown by Figure 4, atmosphere pollution levels during years 2000-2019 varied from "heavily polluted" in 2000 (CAPI=14.18) to "mildly polluted" in 2018 (CAPI=5.85). Average CAPI value during the studied period was equal to 10.23, thus characterizing the atmosphere as "polluted". Primary pollutants that were responsible for high pollution level of open air in Rivne city were: dust, sulfur dioxide, nitrogen dioxide, carbon dioxide during years 2000-2009; dust, carbon dioxide, hydrogen fluoride, phenol and formaldehyde were top-priority during years 2010-2019. In some years nitrogen dioxide too was amongst top pollutants.

After implementation of quarantine measures due to COVID-19 pandemic, industrial production volumes were reduced and traffic of all kinds of transport (which are an important source of open air pollution in Rivne city) was restricted. Due to this we have studied effects of these restrictive measures on the state of open air. Most severe restrictions were in place during March-May 2020, with gradual relaxation of restrictions during June-July of the same year. To achieve the stated goal we have analyzed results of laboratory assessments performed by Complex laboratory of Rivne oblast hydrometeorology centre in Rivne city. To determine the trends of evolution of open air conditions in the city, we have compared data on qualitative composition of air (by top-priority pollutants) for February-April and May-July in 2019 and 2020 correspondingly (Figure 5).

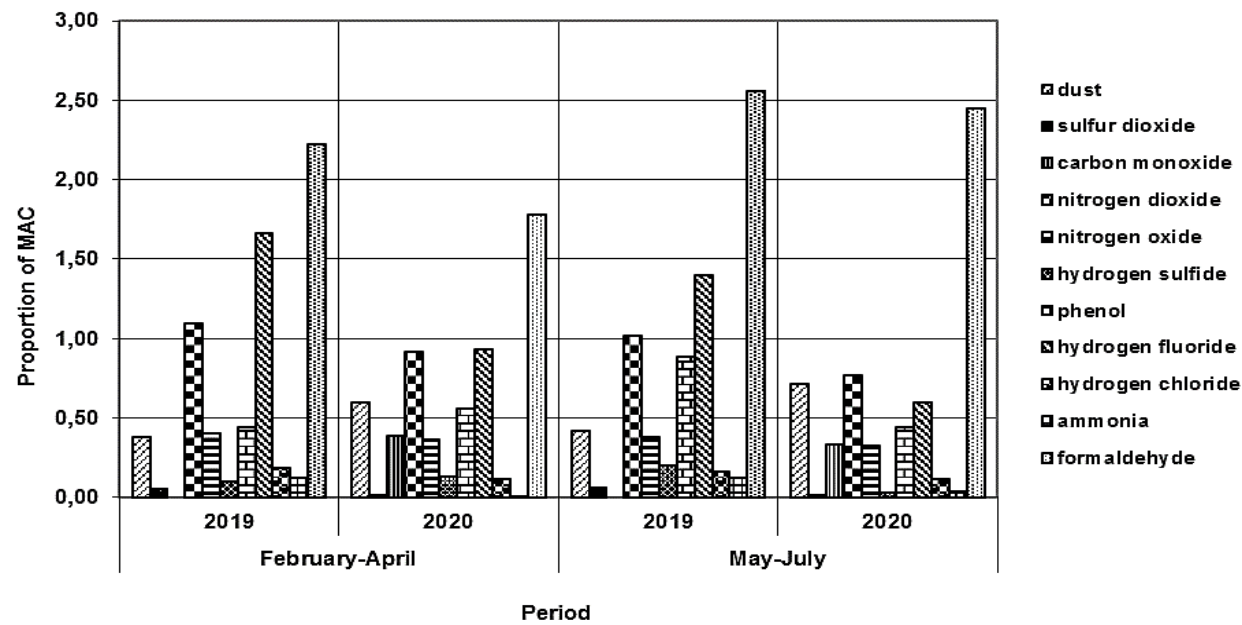

Figure 5. Quality of open air in Rivne city in February-April and May-July periods of 2019 and 2020.

Analysis of data presented at Figure 5 lets us conclude that quarantine measures restricting traffic have improved state of open air to some degree in Rivne city, but after relaxation of restrictions level of air pollution began growing back. Both during February-April of 2020 and during May-July of 2020 concentrations of formaldehyde exceeded MACa.d. level by factor of 1.8 and of 2.4 respectively. Concentrations of the rest of pollutants were in range of 0.01-0.93 of MACa.d.

By comparing these data with data for corresponding periods of 2019 we have determined that MACa.d. was exceeded for nitrogen dioxide (by factor of 1.09 during February-April and by factor of 1.02 during May-July); for hydrogen fluoride - by factor of 1.7 and by factor of 1.4 respectively; for formaldehyde - by factor of 2.2 and by factor of 2.6 respectively.

We have performed CAPI calculation for two studied periods (Fig. 6). 


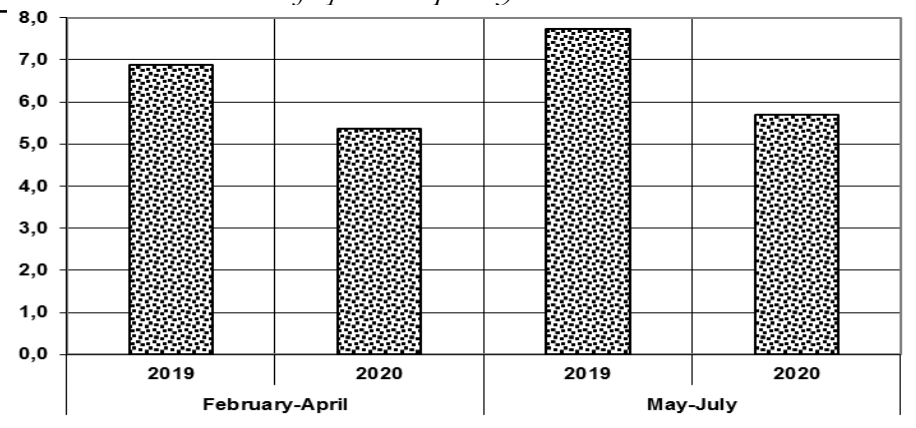

Period

Figure 6. CAPI values in Rivne city during February-April and May-July periods of 2019 and 2020 years.

Complex air pollution index (CAPI) was equal to 5.4 during quarantine restrictions but grew to 5.7 when the restrictions were partially loosened. Air pollution level was evaluated as "mild pollution". During the corresponding periods of 2019 this index was changing from 6.9 ("mild air pollution") to 7.7 ("polluted air") respectively.

We have determined that higher level of open air pollution in May-July period compared to respective February-April period was observed both in 2019, when there were no quarantine restrictions implemented, as well as in 2020 during the quarantine.

As was mentioned above, open air pollution level is determined not only by amounts of pollutant emissions but also by meteorological conditions that influence pollutant transportation, pollutant dispersion and air self-purification processes. Nature of open air pollution is determined by specifics of each individual pollutant and by their dependence on meteorological factors. Due to this we have performed statistical examinations to determine dependency of open air pollutant concentration formation on meteorological conditions using multiple correlation coefficients.

Research was performed using archive materials of Rivne Oblast Hydrometeorology Centre for the 2000-2020 period. Following meteorological parameters were taken into account: air temperature, total atmospheric precipitation, air humidity and wind velocity. List of pollutants and research findings are presented in Table 1.

Table 1. Dependence of pollutant concentration in open air on meteorological conditions in Rivne city.

\begin{tabular}{lcc}
\hline Pollutant name & $\begin{array}{c}\text { Multiple correlation } \\
\text { coefficient value }\end{array}$ & Relationship characteristic \\
Dust & 0.58 & moderate correlation \\
Sulfur dioxide & 0.62 & moderate correlation \\
Nitrogen dioxide & 0.55 & moderate correlation \\
Carbon monoxide & 0.27 & loose correlation \\
Nitrogen oxide & 0.76 & strong correlation \\
Hydrogen sulfide & 0.64 & moderate correlation \\
Phenol & 0.70 & moderate correlation \\
Hydrogen fluoride & 0.44 & loose correlation \\
Hydrogen chloride & 0.80 & strong correlation \\
Ammonia & 0.78 & strong correlation \\
Formaldehyde & 0.51 & moderate correlation \\
\hline
\end{tabular}

Analysis of Table 1 lets us conclude that there is a relationship between concentration of pollutants in open air and meteorological parameters. Strong correlation was exhibited for nitrogen oxide, hydrogen chloride and ammonia: multiple correlation coefficients fall within 0.76-0.80 range; moderate correlation was determined for dust, sulfur dioxide, nitrogen dioxide, hydrogen disulphide, phenol and formaldehyde with multiple correlation coefficients varying in 0.51-0.70 range; weak correlation was found for carbon monoxide and hydrogen fluoride.

\section{Conclusion}

Results of study performed to determine trends of evolution of open air quality in Rivne city during quarantine restrictions imposed due to COVID-19 pandemic have allowed to establish that implementation of quarantine measures has led to improvement of open air quality. Specifically, during the quarantine as well as after relaxation of quarantine measures only concentration of formaldehyde in open air of Rivne city did exceed MACa.d.

Primary source of open air pollution in Rivne city is motor vehicles which comprise $79 \%$ of total amount of pollutant emissions. MACa.d. for concentrations of dust, sulfur dioxide, nitrogen dioxide, hydrogen sulfide and formaldehyde in open air of the city are exceeded by factors of 1.3-32.0. These are the top priority pollutants contributing to atmospheric pollution.

Nature of open air pollution is determined by specifics of each individual pollutant, by its potential for effect summation and by peculiarities of its dispersion depending on meteorological conditions. Dependency of concentration of pollutants emitted into open air on meteorological factors was established. Strong correlation was exhibited for nitrogen oxide, hydrogen chloride and ammonia: their multiple correlation coefficients fall within $0.76-0.80$ range; moderate correlation was seen for dust, sulfur dioxide, nitrogen dioxide, hydrogen disulphide, phenol and formaldehyde with multiple correlation coefficients varying in 0.51-0.70 range.

\section{References}

Adamenko O.M., Kryzhanivsky Ye. I., Neyko Ye. M. (2004). Ecology of the Ivano-Frankivsk city. Ivano-Frankivsk: Suversiya MV. Akimoto, H. (2016) Atmospheric Reaction Chemistry. Asakura Publishing, Springer.

Baharyev V. S., Kortsova O.L., Kostyrya V.V., Marynin D.V. (2012). Study of atmospheric air pollution state in conditions of changes of contemporary real estate development in urban settlements. Collection of research papers «Ecological safety» of Kremenchuk 
Mykhailo Ostrohradskyi National University, 1(13), 43-47.

Boyko V. (2016). Safety of atmospheric air as a constituent of ecological safety of border regions in Western Ukraine. Economist, 3 , 26-30.

Brezhytska, O.A. (2013). Determining impact of urbanized territory on the state of open air in context of sustained development. Bulletin of the National University of Water and Environmental Engineering, 2(62), 61-69.

Herasymchuk Z.V., Oleksyuk A.O. (2007). Ecological safety of the region: diagnostics and facilitation mechanism. Lutsk: Nadstyr'ya. Hvesyk M.A., Stepanenko A.V., Obykhod G.O. (2014). Ecological and natural-technogenic safety of Ukraine in regional dimension. Kyiv: Public Institution "Institute of Environmental Economics and Sustainable Development of the National Academy of Sciences of Ukraine".

Hvesyk M.A., Stepanenko A.V., Symonenko V.K. (2015). Ecological safety of transborder regions of Ukraine in context of European integration. Kyiv: Public Institution "Institute of Environmental Economics and Sustainable Development of the National Academy of Sciences of Ukraine".

Jacobson, M. (2002). Atmospheric pollution. History, science and regulation. New York: Cambridge University Press.

Kachynsky A.B. (2001). Ecological safety of Ukraine: systems analysis of improvement prospects. Kyiv: National Institute for Strategic Studies.

Kiptenko Ye.M., Bashtannyk M.P., Kozlenko T.V., Zhemera N.S., Trachuk N.O. (2013). Estimate of open air pollution state and its prediction in the industrial cities of Ukraine (exemplified by city of Luhansk). Academic papers of Ukrainian Hydrometeorological Institute, 265, 78-89.

Klymenko M.O., Lyko D.V., Pryschepa A. M., Kaskiv M.V. (2018). Estimating the state of Rivne city by cytogenetic monitoring indicators. Rivne: NUWEE.

Klymenko M.O., Pryschepa A.M., Vozniuk N.M. (2006). Environmental monitoring. Kyiv: Publishing center "Academy".

Kucheryavy V.P. (1999). Urboecology. Lviv: Svit.

Lazaridis, M. (2011). First Principles of Meteorology and Air Pollution. Springer Science + Business Media P.V.

Liss, P.S., Johnson, M.T. (2014) Ocean- Atmosphere Interaction of Gases and Particles. Springer Heidelberg.

Liu, Z.R., Hu, B., Wang, L.L et al. (2015). Seasonal and diurnal variation in particulate matter (PM10 and PM2.5) at an urban site of Beijing: analyses from a 9-year study, Environ. Sci. Pollut. Res., 22, P. 627-642.

Moller, D. (2010). Chemistry of the Climate System. Walter de Gruyter GmbH \& Co, Berlin.

Novikov Yu.V. (2005). Ecology, environment and human. Moscow: FAIR-PRESS.

Pryschepa A.M., Borschevska I.M., Budnik Z.M., Brezhytska O.A, Kurilyuk O.M. (2017). Bioindicational assessment of state of atmospheric environment of Rivne city on basis of analysis of fluctuating asymmetry. Student bulletin of NUWEE, 4(80), 30-38.

Shevchuk V.Ya., Satalkin Yu. M., Bilyavsky G.O. (2004). Ecological managemeny. Kyiv: Lybyid.

\section{Citation:}

Budnik, Z.M., Sobko, Z.Z., Vozniuk, N.M., Lykho, O.A., Pryshchepa, A.M. (2020). Evolution of open air quality of urbanized territories under Covid-19 pandemic conditions. Ukrainian Journal of Ecology, 10(6), 48-53.

\begin{tabular}{|l|l}
\hline$(\mathrm{cc}) \mathrm{EY}$ \\
$\mathrm{EY}$
\end{tabular} This work is licensed under a Creative Commons Attribution 4.0. License 